\title{
A arquitetura moderna diante da esfinge ou a nova monumentalidade - uma análise do Monumento Nacional aos Mortos na Segunda Guerra Mundial, Rio de Janeiro
}

Ricardo de Souza Rocha ${ }^{1}$

RESUMO: $O$ presente trabalho pretende analisar o Monumento Nacional aos Mortos na Segunda Guerra Mundial (1 956-60), projeto de Marcos Konder Netto e Hélio Ribas Marinho, localizado no Parque do Flamengo, no Rio de Janeiro. Inicialmente, são feitos comentários a respeito dos debates, no interior do Movimento Moderno, sobre a necessidade de uma nova monumentalidade; em seguida, são discutidas a inserção da obra no contexto urbano do Rio de Janeiro e sua materialidade específica; finalmente, é proposta uma hipótese para a compreensão do monumento moderno.

PALAVRAS-CHAVE: Arquitetura moderna. Monumentos. Monumento Nacional aos Mortos na Segunda Guerra Mundial. Marcos Konder Netto. Hélio Ribas Marinho. Rio de Janeiro.

ABSTRACT: The purpose of this paper is to analyze the National Memorial to the World War II Dead (1956-60), a monument designed by Marcos Konder Netto and Hélio Ribas Marinho, and located in Flamengo Park, Rio de Janeiro. We start by commenting on the debates that were going on within the Modernist movement about the need for a new monumentality. Then, we examine the memorial against the urban landscape of Rio de Janeiro and its specific architectural language. Finally, we make an effort to explain the apparent paradox found in modern monuments.

KEYWORDS: Modern Architecture. Monuments. Second World War National Memorial. Marcos Konder Netto. Hélio Ribas Marinho. Rio de Janeiro.

\footnotetext{
1. Docente do Departamento de Arquitetura e Urbanismo / Centro de Tecnologia, Universidade Federal de Santa Maria, Cidade Universitária / Bairro Camobi, 97105-900, Santa Maria - RS. E-mail: $<$ rdsr8@hotmail.com>.
} 
2.Lewis Mumford, por exemplo, pregará "a morte do monumento" (HANDLIN, 2004, p. 234-235), chegando mesmo a afirmar (em The Culture of Cities) que "se é um monumento não é moderno, se é moderno não é um monumento" (Apud CONDURU, 2006, p. 69). Posteriormente, escreverá Monumentalism, symbolism and style (RIGOTTI, 1999).

3. Claro está que a referência aqui é (principalmente) o monumento intencional: uma obra realizada intencionalmente com o objetivo de ser um monumento, tenha ou não o propósito de homenagear um acontecimento, data ou personagem (a questão que se levanta, portanto, é o problema da representação simbólica de valores). E menos o monumento bistórico: ou as obras com ou sem valor artístico que representam um estágio qualquer da cultura humana, independentemente da intenção em sua origem.

4. Não é à toa que Lucio Costa é convidado a discutir o tema em The Architectural Review, em 1948 (RIGOTTI, 1999, p. 84).

5. Lembrando que, em grande parte, principalmente em países periféricos como o Brasil, a produção de arquitetura ainda é bastante "artesanal", embora não mais balizada pela excelência artística.
Monumentos são obras criadas pelo homem como símbolos de seus ideais, buscas e ações.

Eles tencionam sobreviver aos períodos que os originaram, constituindo uma herança para as gerações futuras.

Sigfried Giedion

Em um primeiro momento, a idéia de um monumento moderno parece constituir um paradoxo ${ }^{2}$. Admitindo-se que um monumento é um mecanismo de acrisolamento e transmissão de valores e, de certa maneira, a expressão da autoridade que deles emana, um monumento moderno estaria em desacordo com a idéia da modernidade como sendo caracterizada, justamente, pela dissolução de toda autoridade heterônoma, isto é, não reconhecida de forma livre e autônoma pelo sujeito ${ }^{3}$.

Para Conduru (2006, p. 68):

Qualificar como monumental uma obra de arquitetura moderna é, de certo modo, um problema. A princípio, a questão da monumentalidade estava interditada à arte do modernismo. [...] A exigência monumental seria [...] uma ameaça à autonomia da arte frente aos poderes político, religioso, econômico ou de qualquer outra natureza. [...] Além disso, [...] a prática de constante transformação [seria] característica da arte na modernidade.

Não obstante: a. desde o início, o tema do monumento não esteve ausente da paleta projetual dos pioneiros do Movimento Moderno - basta lembrar - Monumento a Terceira Internacional (1919-1920), de Vladimir Tatlin, que nunca saiu do papel ou os construídos Monumento aos Caídos de Março (19211922) de Walter Gropius e o Monumento a Karl Liebknecht e Rosa Luxemburgo (1926), de Mies van der Rohe; e b. nos anos 1940, como será comentado adiante, a questão da (nova) monumentalidade estará no centro do debate arquitetônico internacional ${ }^{4}$.

Contudo, como nota Joly (1998, p. 368-370), a arquitetura moderna alterará a linguagem do monumental. A produção industrial ${ }^{5}$ tirara de cena a excelência artística (de caráter artesanal) e, de quebra, a antiga linguagem figurativa e simbólica. Tal aspecto pôde ser em parte contrabalançado pela "síntese das artes" tal como proposta por, entre outros, Le Corbusier. Entretanto, uma outra questão era mais difícil de ser enfrentada: na cidade (ideal) da arquitetura moderna, um conjunto de objetos isolados em um parque, a dialética entre edificações anônimas (indiferenciáveis na massa contínua de construções) e monumentos (objetos em destaque) era mais complicada.

Nesse sentido, o presente trabalho pretende analisar o Monumento Nacional aos Mortos na Segunda Guerra Mundial (1956-1960) - projeto de Marcos Konder Netto e Hélio Ribas Marinho, localizado no Parque do Flamengo, no Rio de Janeiro - a partir dos seguintes aspectos: inicialmente, procurando situá-lo em relação aos debates no interior do Movimento Moderno, principalmente na década de 1940, sobre a necessidade de uma "nova monumentalidade"; 
em seguida, tratando da obra no contexto urbano do Rio de Janeiro, como forma de perceber como a nova monumentalidade se insere na (tirando proveito da) cidade "tradicional"; para então abordar sua materialidade específica - ou como se constituiu a linguagem do monumento moderno, ao ser abandonada a linguagem figurativa e simbólica do monumento tradicional; finalmente, procurando compreender o paradoxo apontado inicialmente, tal como ele se revela pela análise do objeto.

Por uma nova monumentalidade

Para muitos, o entre guerras pode ser caracterizado como a "era monumental" (HEATHCOTE, 1999), em função da arquitetura dos regimes totalitários (ltália, Alemanha e União Soviética) e do fenômeno da "Nova Tradição" - expressão cunhada por Henry-Russell Hitchcock em 1929 e que se refere ao historicismo modernizado que se desenvolveu no espaço deixado pelo vazio de representação simbólica de grande parte da abstração formal moderna. Se ambos os casos podem ser associados à noção de modernização conservadora ou à de modernismo reacionário (HERF, 1993), a arquitetura moderna, cujas premissas são opostas, viu-se obrigada, não obstante, a também enfrentar a questão da monumentalidade.

No ano da publicação do catálogo Brazil Builds, de Philip Goodwin ( 1943), acompanhando a exposição itinerante homônima iniciada no Museu de Arte Moderna de Nova lorque, Siegfried Giedion, Fernand Léger e José Luis Sert elaboram, na mesma cidade, seus Nine points on monumentality. A coincidência é reveladora

Goodwin (1943, p. 91): Enquanto o clássico dos edifícios federais de Washington, o arqueológico da Academia Real de Londres e o clássico nazista de Munich dominam triunfantes, o Brasil teve a coragem de quebrar a rotina e tomar um rumo novo dando como resultado poder o Rio orgulhar-se de possuir os mais belos edifícios públicos do continente americano.

Giedion: As pessoas desejam que os prédios representativos de sua sociedade e de sua vida comunitária preencham mais do que requisitos funcionais [tradução livre pelo autor] (Apud FRAMPTON, 1985, p. 233).

Para Goodwin - que põe no mesmo saco as democráticas Washington e Londres e a nazista Munique, em um ataque evidente às correntes arquitetônicas conservadoras ${ }^{7}$ - o regime político parece importar menos que sua expressão arquitetônica, lembrando o fato de que a "coragem" brasileira era patrocinada por um regime ditatorial. Já Giedion, em The need for a new monumentality

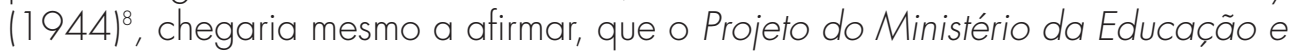
Saúde (Rio de Janeiro, 1936-1945) - de agora em diante referido como MES - de Lucio Costa, Oscar Niemeyer, Affonso Eduardo Reidy, Jorge Machado Moreira, Carlos Leão, Ernani Vasconcelos (e Le Corbusier), era um importante
6.Jorge Liernur (1999, p. 35) aponta a relação entre tais fatos, mas sem sugerir sua enorme coincidência:"la valorización internacional de las obras presentadas en $\mathrm{Bra}$ zil Builds recibió un ulterior impulso a partir de su articulación con el debate acerca de la 'Nueva Monumentalidad".

7. No press-release da exposição tal ataque é ainda mais claro:"enquanto o estilo clássico impera em Washington; a arqueologia da Academia Real, em Londres; o classicismo nazista, em Munique; e o neo-imperial, em Moscou, $o$ Brasil teve a coragem de sair do campo do fácil conservadorismo.A sua corajosa libertação do tradicionalismo eliminou a antiquada rotina do pensamento governamental e estabeleceu o princípio livre da construção criadora. As capitais do mundo que necessitarão ser reedificadas após a guerra não podem encontrar melhor modelo do que os moderníssimos edifícios da capital do Brasil" [grifos meus] (Apud LISSOVSKY, 1996, p. xii).

8.Apud Carlos Comas (1987, p. 142). 
passo na inadiável tarefa de retomada do sentido de monumentalidade pela arquitetura moderna. Daí a necessidade de crítica ao funcionalismo estéril e a abertura ao jogo simbólico das formas, temas que foram levados, inclusive, aos CIAM (Congrès Internacionaux d'Architecture Moderne) - apesar de algumas vozes dissonantes.

Onde Frampton (1985, p. 222) vê apenas uma ironia, "o fato de que o enterro da Nova Tradição e o triunfo do Movimento Moderno coincidam com uma reação em favor da [nova] monumentalidade vindo do seio do próprio movimento"; é necessário esfregar os olhos e perceber que, menos do que uma coincidência, tal fato foi providencial ao destino da modernidade arquitetônica naquele momento. E, desse ponto de vista, os arquitetos brasileiros se encontravam na vanguarda internacional da busca da expressão monumental moderna.

Monumento moderno e cidade

Contraditoriamente, a cidade tradicional é fundamental para o monumento moderno. Como outros já observaram antes ICOMAS, 1987, p. 144) muito da presença destacada do MES se deve ao contraponto que ele estabelece com o tecido ao seu redor, que deve algo de sua configuração ao Plano Agache. Nesse sentido, é interessante analisar como a dialética entre monumento e espaço urbano é tratada em Brasília, cidade moderna por excelência.

Como é de conhecimento geral, o Plano Piloto de Brasília define-se basicamente pelo cruzamento de dois eixos: monumental e residencial. Se na cidade tradicional era o tecido contínuo - constituído pela repetição de construções comuns - que estabelecia uma matriz neutra como forma de destacar espaços públicos e monumentos, na cidade moderna, composta unicamente de objetos isolados em um grande espaço aberto, é a homogeneidade de tratamento das edificações do setor residencial junto com a técnica paisagística que procuram criar um pano de fundo, interrompido unicamente no eixo monumental.

Tal estratégia, como Jano, possui duas faces: o caráter especial do setor monumental é reforçado; mas, por outro lado, a vida cotidiana no setor residencial se desenvolve de maneira autônoma e resguardada - o arqueamento do eixo residencial, inclusive, permite apenas perspectivas parciais, nunca dirigidas a um objeto específico, como acontece no eixo monumental.

Como sugestão ao código de obras de Brasília, Lucio Costa chega mesmo a tentar garantir ao máximo o caráter de pano de fundo autônomo do setor residencial, para que este não interfira e nem receba interferências do setor monumental. Para isso, sugere, entre outras coisas, que nas edificações:

3.2. - O partido deve ser claro, e as formas devem ser simples; deve haver sobriedade no emprego de elementos e no de materiais diferentes; 3.3 - o projeto não pode ser: complicado, extravagante, pretensioso ou rebuscado; 4. 1. - As formas usadas nas estruturas monumentais não podem ser transpostas para a escala residencial (COSTA, 1962, p. 325). 
No caso do "Monumento aos Pracinhas" - ainda que imprecisa essa é a maneira mais comum pela qual o monumento é conhecido ${ }^{9}$ - está claro que sua condição de cartão postal é tributária de sua localização no Parque do Flamengo. Essa espécie de versão carioca do Ibirapuera, principal obra do IV Centenário do Rio de Janeiro (1965), injetou, inclusive, algo de seu caráter no monumento, que, desse modo, conjuga lazer e civismo.

Entretanto, embora inserido em um tramo de cidade moderna possivelmente o conjunto urbano moderno mais importante do país depois da capital federal - de modo semelhante ao MES, esse tramo como um todo ganha significado em contraponto com o tecido ao seu redor, principalmente, o centro do Rio de Janeiro ${ }^{10}$.

Por outro lado, iá em 1957, um decreto garantia a condição privilegiada do monumento, declarando seu entorno como área non aedificandi. E o processo de tombamento do parque, realizado por Paulo Santos em 1965, apontava:

O perigo maior consiste na inclusão futura na área ajardinada de pavilhões de diversões, restaurantes, cinemas e quejandas edificações, como assim de bustos de figuras nacionais, etc. Inclusão que tendo a justificá-la o interesse prático ou cívico das iniciativas poderá sacrificar irremediavelmente a beleza do conjunto ${ }^{11}$.

De fato, em meados da década de 1980, foi barrada a idéia de localizar no parque, em frente ao Morro da Viúva, o Monumento Tortura Nunca Mais, concebido por Oscar Niemeyer. A reprodução de objetos soltos ao longo do local poderia fazer com que ele se tornasse um museu a céu aberto, com uma sucessão de formas plásticas variadas, eventualmente desconexas. Se isso pode ter sido um dos motivos para a recusa do monumento de Niemeyer, treze anos antes, curiosamente, havia sido permitida a construção do Monumento a Estácio de Sá, projeto de Lucio Costa - nesse sentido, a razão do embargo a Niemeyer, para além da qualidade duvidosa de sua proposta ${ }^{12}$, que gerou bastante polêmica na época, talvez tenha sido a possibilidade algo inusitada de um mesmo lugar abrigar um monumento homenageando militares próximo a um monumento contra os abusos por eles cometidos.

moderno monumento aos mortos

Michel Vovelle (1987, p. 83-84) aponta que o modelo "contemporâneo" do monumento aos mortos pode ser caracterizado por

Uma igualização progressiva [do monumento ao general vitorioso ao túmulo do soldado desconhecido], diluindo seu caráter até então cruelmente hierarquizado; e também uma difusão cada vez maior, ligada ao fato de que o obscurecimento do caráter religioso ou expiatório torna o monumento coletivo mais apto a transmitir uma mensagem política funcional.
9. Imprecisa na medida em que o monumento homenageia apenas os pracinhas mortos em combate. Lamentavelmente, aliás, passado o período de homenagens no retorno do conflito e descontando-se sua participação eventual em desfiles militares, o tratamento dispensado aos pracinhas sobreviventes não foi tão honroso como o conferido aos mortos. Ver Francisco Ferraz (2005).

10. Não deixa de ser um dado curioso o fato de que, de acordo com Marcos Konder, o alinhamento entre o "pórtico" do monumento e o Obelisco da Avenida Rio Branco foi acidental.Ainda que Konder faça a ressalva de que um colaborador do projeto na época, o arquiteto Hírcio Fermo de Miranda, garanta que ele foi intencional. Entrevista ao autor em 5 abr. 2004.

11. Processo de tombamento 748-T-64 DPHAN/ DET - Seção Histórica. Paulo Santos chegou mesmo a sugerir ainda "o tombamento da área marítima abrangida pelo parque até $100 \mathrm{~m}$ da praia, em toda extensão, a fim de evitar se possam erguer ali no futuro construções espúrias que igualmente poderão sacrificar a beleza do conjunto".

12. Cf. Geraldo G. da Silva (1989). 
13. Segundo Octavio Costa (1976, p. 85), em 1976 existiam "mais de duas centenas de monumentos erguidos à FEB em pouco menos de duzentos municípios".
Em uma frase: democratização e funcionalização da representação da morte em favor dos vivos. Dada a tímida participação brasileira na Primeira Guerra Mundial, o fenômeno da proliferação de monumentos aos mortos, observado por vários autores em relação àquele conflito (SHERMAN, 1999; PROST, 1997), ocorre nesse momento no Brasil'13. Na contramão, portanto, do que Vovelle (1987) identificou como o ciclo de nascimento, vida e morte do monumento "comemorativo", que se encerraria no segundo pós-guerra com a anulação das fórmulas triunfalistas, com a construção de monumentos abstratos e antimonumentos.

Sendo praticamente o único a aparecer nos manuais sobre a arquitetura moderna brasileira, o Monumento Nacional aos Mortos na Segunda Guerra Mundial é uma das obras, em relação ao tema do monumento, que alcançaram maior repercussão no país. Evidentemente tal repercussão está associada à forte presença da campanha da Força Expedicionária Brasileira (FEB) no imaginário nacional - ou nacionalista - oficial. A idéia do sacrifício pela liberdade e pela pátria, tal como cantada no hino, pode parecer um tanto empoeirada hoje, mas no imediato pós-guerra, com a comoção provocada pelas oitocentas baixas somados os mortos nos torpedeamentos, incluindo os da Marinha Mercante -e os quase três mil feridos e acidentados (COSTA, 1976), a situação era bem diferente.

O Monumento aos Pracinhas insere-se, assim, na confluência de várias séries: desde a mais geral, relacionada aos monumentos aos mortos ou caídos em conflitos - que admite uma subdivisão por tipos: fúnebre, patriótico etc. (PROST, 1997; AGULHON, 1979); passando pela série dos "monumentos ao expedicionário"; incluindo a que se refere especificamente ao "monumento ao Brasil na Guerra" ou ao "monumento nacional aos mortos na Segunda Guerra Mundial" - da qual faz parte ainda o bem menos conhecido Monumento Votivo Militar Brasileiro (1967), projeto de Olavo Redig Campos, localizado no Cemitério de Pistóia, na ltália, onde permaneceram os restos mortais dos combatentes brasileiros até sua transladação para o Monumento aos Pracinhas - e chegando até à que diz respeito aos monumentos modernos.

A obra

Abandonados o projeto do escultor Edgar Duvivier para o Monumento ao Brasil na Guerra (fruto de um concurso realizado em 1945, sob a iniciativa do Instituto dos Professores Públicos e Particulares do Rio de Janeiro) e a idéia da adaptação do Panteão Militar (atual "Pantheon" de Caxias) para esse mesmo fim, a Comissão de Repatriamento dos Mortos do Cemitério de Pistóia, presidida pelo Marechal Mascarenhas de Moraes (ex-comandante da FEB), opta pela realização de um novo concurso no final de 1955.

O júri era composto pelos seguintes nomes: Roberto Burle Marx; Paulo Antunes Ribeiro, representante do Instituto de Arquitetos do Brasil; engenheiro 
Antônio Alves de Noronha (Clube de Engenharia); engenheiro Hermínio Andrade e Silva (Prefeitura do Distrito Federal); professor Gerson Pompeu Pinheiro (Escola Nacional de Belas Artes); professor Carlos Del Negro (Faculdade Nacional de Arquitetura); e o coronel e engenheiro Aristóbulo Codevilha Rocha (Ministério da Guerra). $\bigcirc$ terreno escolhido, em substituição ao proposto pela Prefeitura na Ponta do Calabouço, localizava-se em frente à praça Paris, no local do Altarmonumento para o Congresso Eucarístico Internacional (1955), obra efêmera concebida por Lucio Costa e realizada por Alcides Rocha Miranda, Elvin Mckay Dubugras e Fernando Cabral. O programa previa um local para os jazigos, um túmulo ao soldado desconhecido, um museu, um espaço para o corpo da guarda e administração, e treze temas para homenagens, que deveriam ser tratados plasticamente.

museu do monumento possui fotografias dos projetos de vinte e oito concorrentes, mas, excetuando-se os finalistas, não há identificação dos autores. Entre tais propostas, é possível encontrar desde uma pirâmide, passando por edificações em forma de capacete ou do símbolo da República; composições mais ou menos tradicionais ou ingênuas (Figura 1); cascas à Niemeyer (Figura 2); e até soluções mais geométricas, uma ou duas quase antecipando a poética da arquitetura paulista da década seguinte.

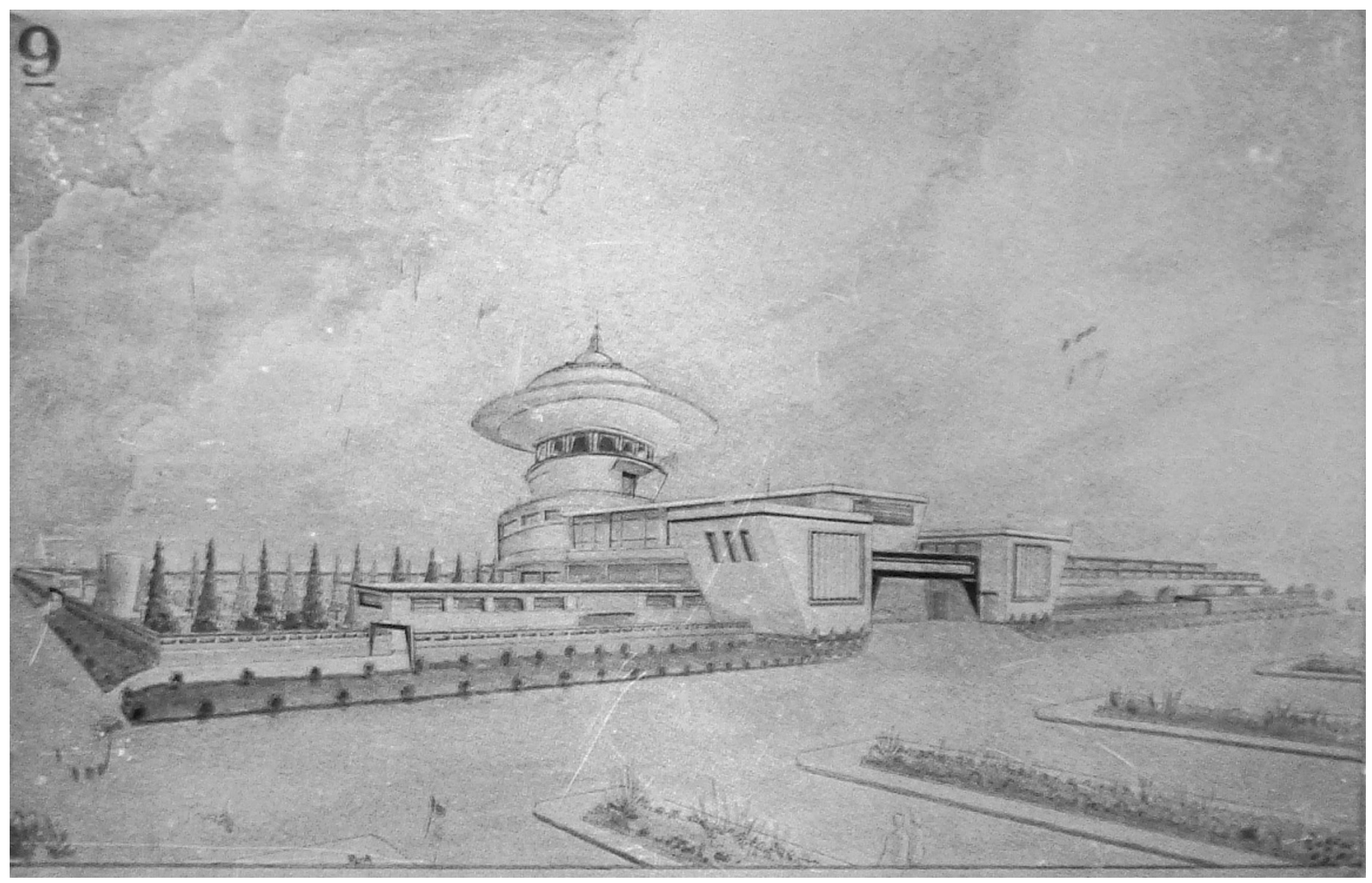

Figura 1 - Proposta apresentada no Concurso para o Monumento aos Mortos na Segunda Guerra Mundial. Perspectiva. Acervo do Museu do Monumento aos Mortos da ll Guerra, Rio de Janeiro. Reprodução do autor. 


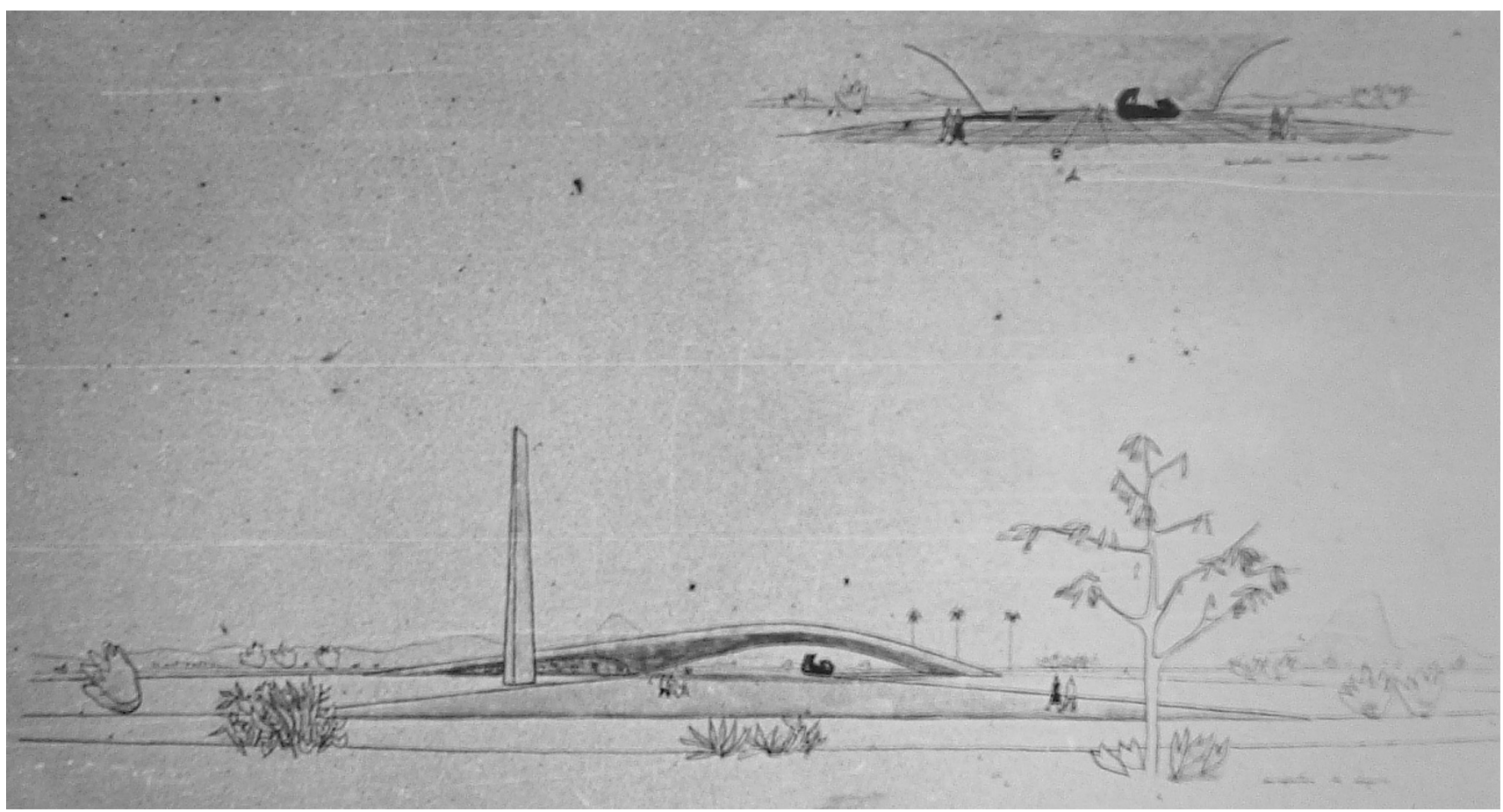

Figura 2 - Proposta apresentada no Concurso para o Monumento aos Mortos na Segunda Guerra Mundial. Perspectiva. Acervo do Museu do Monumento aos Mortos da II Guerra, Rio de Janeiro. Reprodução do autor.

14. Arquiteto pela FNA (1950), trabalhou com Jorge Machado Moreira, Sérgio Bernardes e Reidy (juntamente com Hélio Ribas Marinho e Flávio Marinho Rego).

15. Graduado na FNA em 1948, além de Reidy e Carmem Portinho, trabalhou com Niemeyer, Irmãos Roberto, Henrique Mindlin e Sérgio Bernardes. Entrevista ao autor em dez. 2003.

16.Arquiteto (FNA, 1948) nascido no Piauí, fez o curso de Desenho e Artes Gráficas da Fundação Getúlio Vargas, tendo realizado painéis e murais, por exemplo, para o Conjunto do Pedregulho (1947), de Reidy, e o Educandário São Silvério (Cataguases, 1956), de Francisco Bolonha. Foi professor na FAU/ UFRJ e atuou também como cenógrafo no
Para além dos projetos das cinco equipes finalistas no concurso, foi identificado o de Alcides Rocha Miranda e, de acordo com matéria da época, José de Souza Reis também teria participado do certame.

Na segunda etapa do concurso foram selecionadas as propostas de Marcos Konder Netto ${ }^{14}$ e Hélio Ribas Marinho ${ }^{15}$, com a colaboração de Alfredo Ceschiatti, Anísio Medeiros ${ }^{16}$ e Julio Catelli Filho ${ }^{17}$; Francisco Bolonha, com a participação de Alfredo Volpi e Bruno Giorgi; Heitor Maia Neto ${ }^{18}$, com Francisco Brennand e Abelardo da Hora; Almir Gadelha e Osny Nunes (Figura 6), e; Stephan Cleóbulo Eleutheriadis. Os cinco projetos foram expostos no Museu Nacional de Belas Artes em agosto de 1956 (Figuras 3 a 7).

É possível dividir os projetos finalistas ${ }^{19} \mathrm{em}$ dois grupos: os que deixam a vista da baía mais ou menos desimpedida (Marcos Konder \& Helio Ribas; Bolonha; e Gadelha \& Nunes) e os que a obstruem (Maia Neto; e Stephan Cleóbulo). No projeto vencedor de Konder \& Marinho, a questão das visuais era resolvida com o desimpedimento parcial do nível do solo, somando-se ao de uma plataforma (solução, não obstante, antecipada por Grandjean de Montigny um século antes; ver adiante). Tais preocupações são claramente expostas no memorial dos arquitetos (MARINHO; NETTO, 1956), que rejeitam tanto a solução "enterrada" como a do tipo "centro cívico" e a descontinuidade 


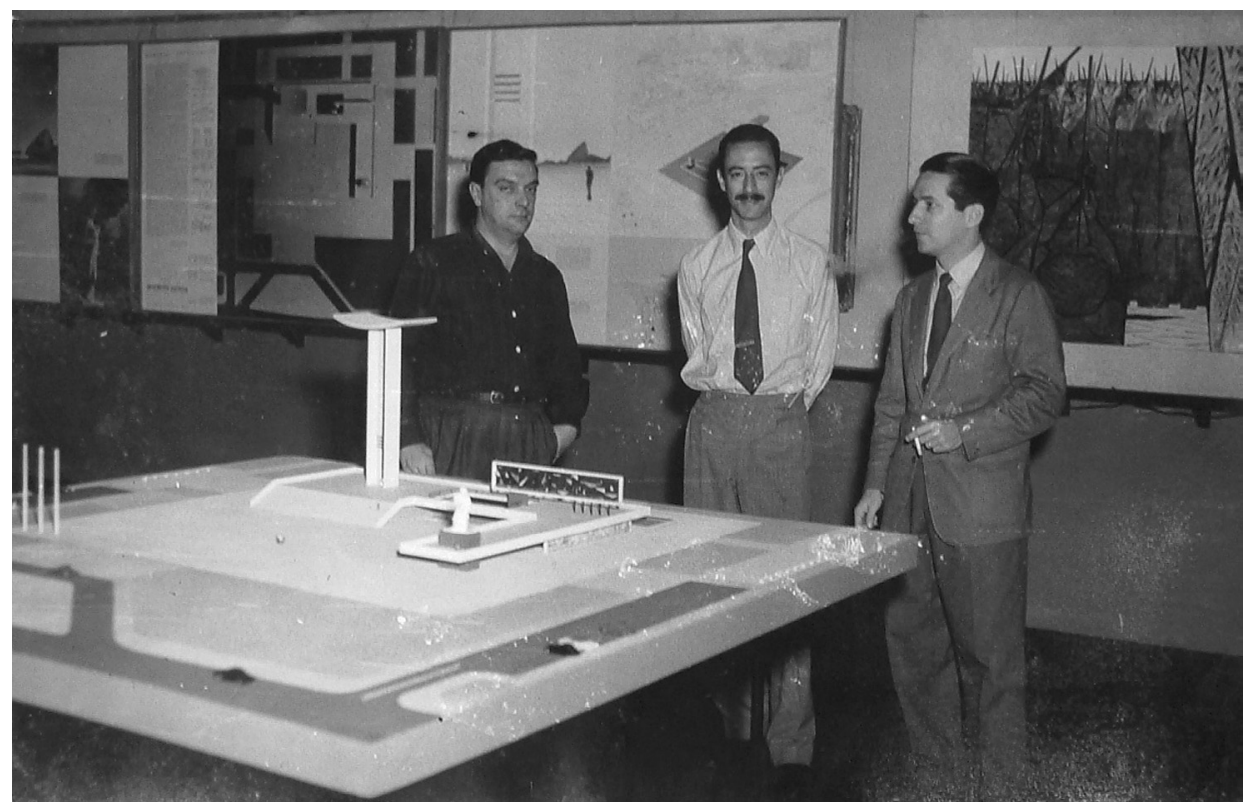

teatro e no cinema. Era colega de turma de Hélio Ribas.

17. Colega de turma de Marcos Konder.

18. Formado pela Escola de Belas Artes de Pernambuco em 1952.

19. Na verdade, rigorosamente falando, seriam três os projetos finalistas - Maia Neto, Bolonha e Konder \& Marinho - os únicos, aliás, publicados em revistas especializadas na época.

Figura 3 - Da esquerda para a direita, atrás da maquete da equipe, apresentada no Concurso para o Monumento aos Mortos na Segunda Guerra Mundial: Ceschiatti, Helio Ribas e Marcos Konder. Acervo do Museu do Monumento aos Mortos da ll Guerra, Rio de Janeiro. Reprodução do autor.

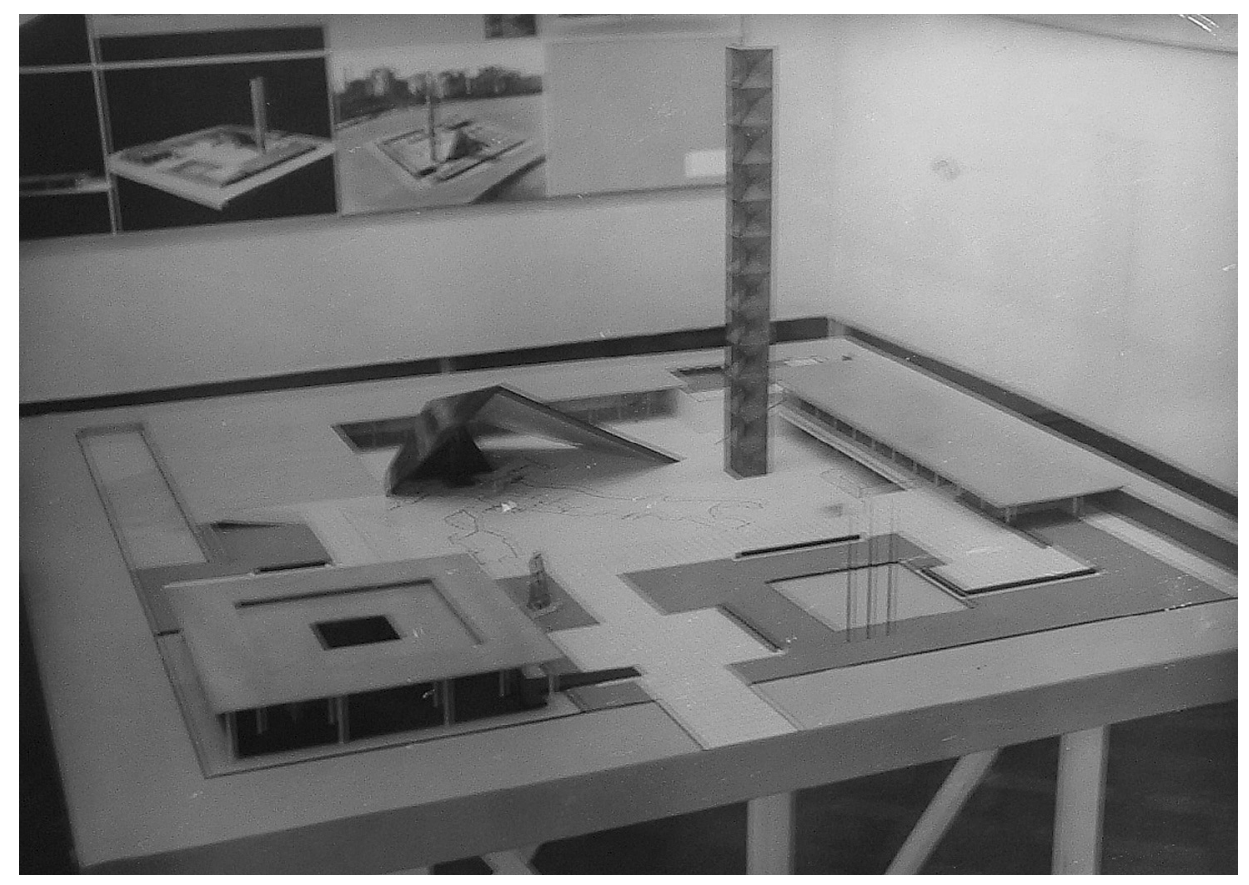

Figura 4 - Francisco Bolonha. Proposta apresentada no Concurso para o Monumento aos Mortos na Segunda Guerra Mundial. Maquete. Acervo do Museu do Monumento aos Mortos da II Guerra, Rio de Janeiro. Reprodução do autor. 


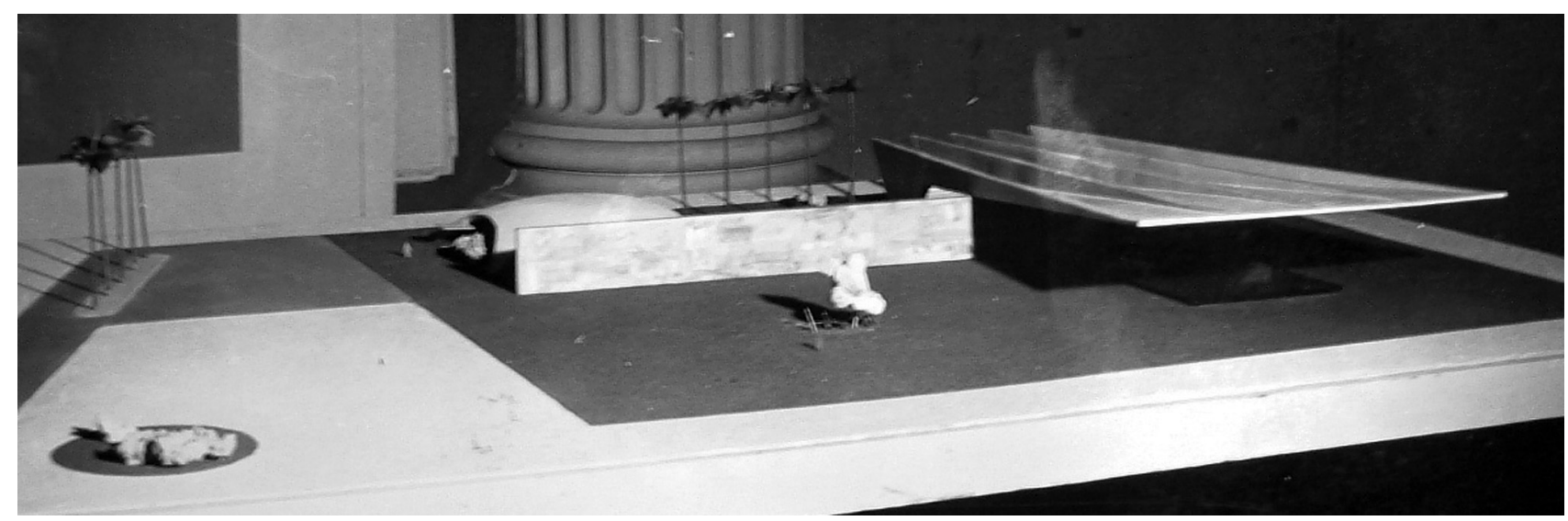

Figura 5 - Heitor Maia Neto. Proposta apresentada no Concurso para o Monumento aos Mortos na Segunda Guerra Mundial. Maquete. Acervo do Museu do Monumento aos Mortos da ll Guerra, Rio de Janeiro. Reprodução do autor.

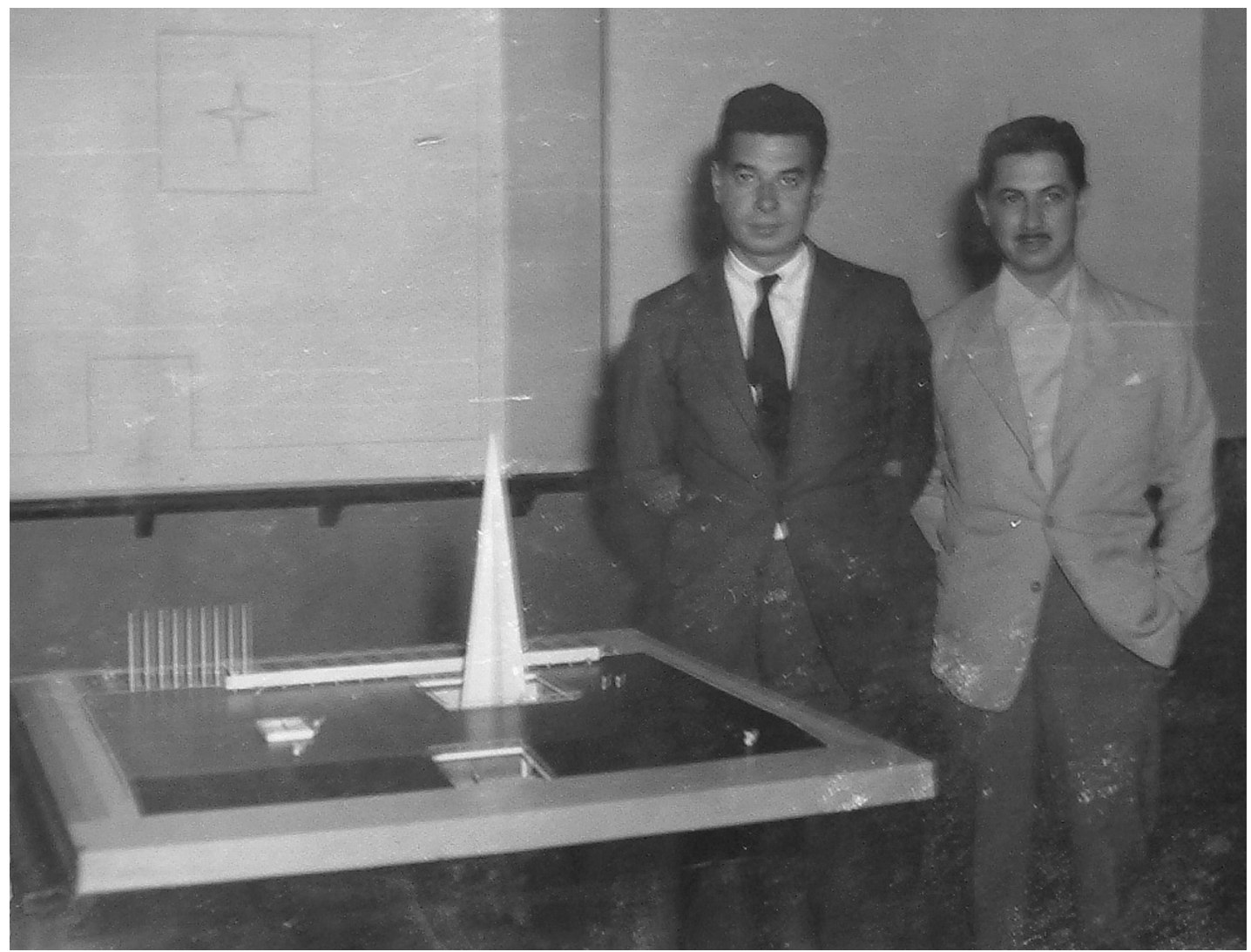

Figura 6 - Almir Gadelha e Osny Nunes. Proposta apresentada no Concurso para o Monumento aos Mortos na Segunda Guerra Mundial. Maquete. Acervo do Museu do Monumento aos Mortos da II Guerra, Rio de Janeiro. Reprodução do autor. 


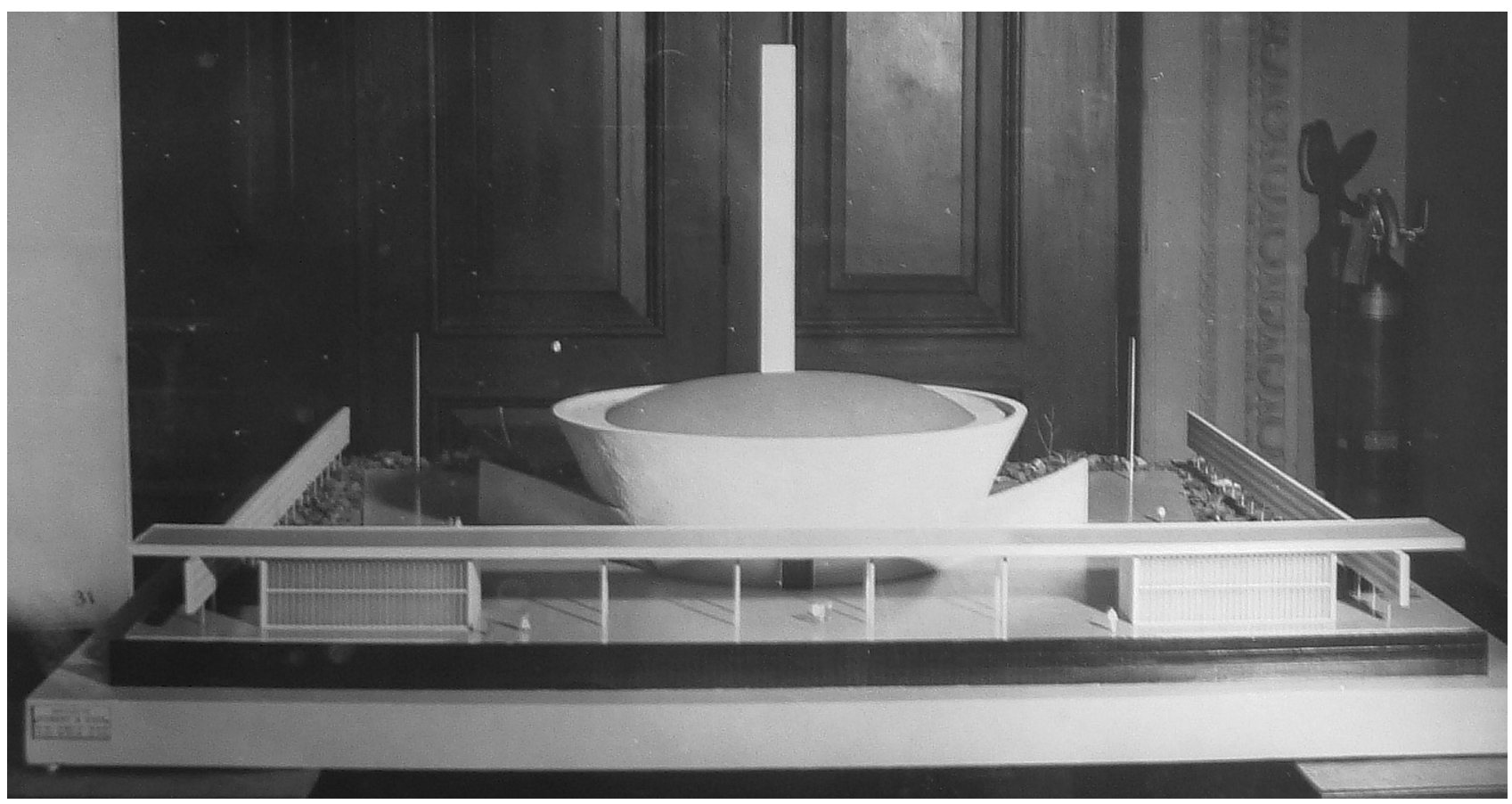

Figura 7 - Stephan Cleóbulo. Proposta apresentada no Concurso para o Monumento aos Mortos na Segunda Guerra Mundial. Maquete. Acervo do Museu do Monumento aos Mortos da II Guerra, Rio de Janeiro. Reprodução do autor.

do piso da praça com seu rebaixamento (como no projeto de Bolonha) ou elevação (caso da proposta de Gadelha \& Nunes) - segundo eles, inadequado para as grandes solenidades.

Não é improvável que a relação arquitetura-paisagem tenha sido determinante na escolha do ganhador do concurso. Nesse aspecto, entre os finalistas, os projetos de Maia Neto e de Stephan Cleóbulo ficavam em desvantagem. E, ao que parece, o júri concordou com as observações de Konder \& Ribas sobre o problema das grandes solenidades.

Os arquitetos propuseram, assim, uma plataforma elevada - em $L-$, onde, ao final de uma escadaria monumental, fica o túmulo do soldado desconhecido ${ }^{20}$, protegido por dois pilones encimados por laje curva (Figura 8); nela se localiza ainda a escultura em metal homenageando a aeronáutica, de Júlio Catelli, o grupo escultórico principal, de Ceschiatti, e uma "pirâmide" com os nomes das pessoas envolvidas na construção do monumento.

No nível da praça, abraçada pela plataforma, encontra-se o museu (atrás da escadaria monumental), internamente adornado com afresco de Anísio Medeiros, e a entrada para o mausoléu, ladeada por dois painéis de azulejos do mesmo artista, homenageando as marinhas de Guerra e Mercante; além de um pequeno jardim, com um roteiro estilizado da campanha da FEB e um espelho d'água em cascatas, na parte posterior. No subsolo, com acessos independentes,
20. O acesso via escadaria monumental foi pensado para ter um sentido de submissão. Entrevista de Marcos Konder ao autor em 5 abr. 2004 . 


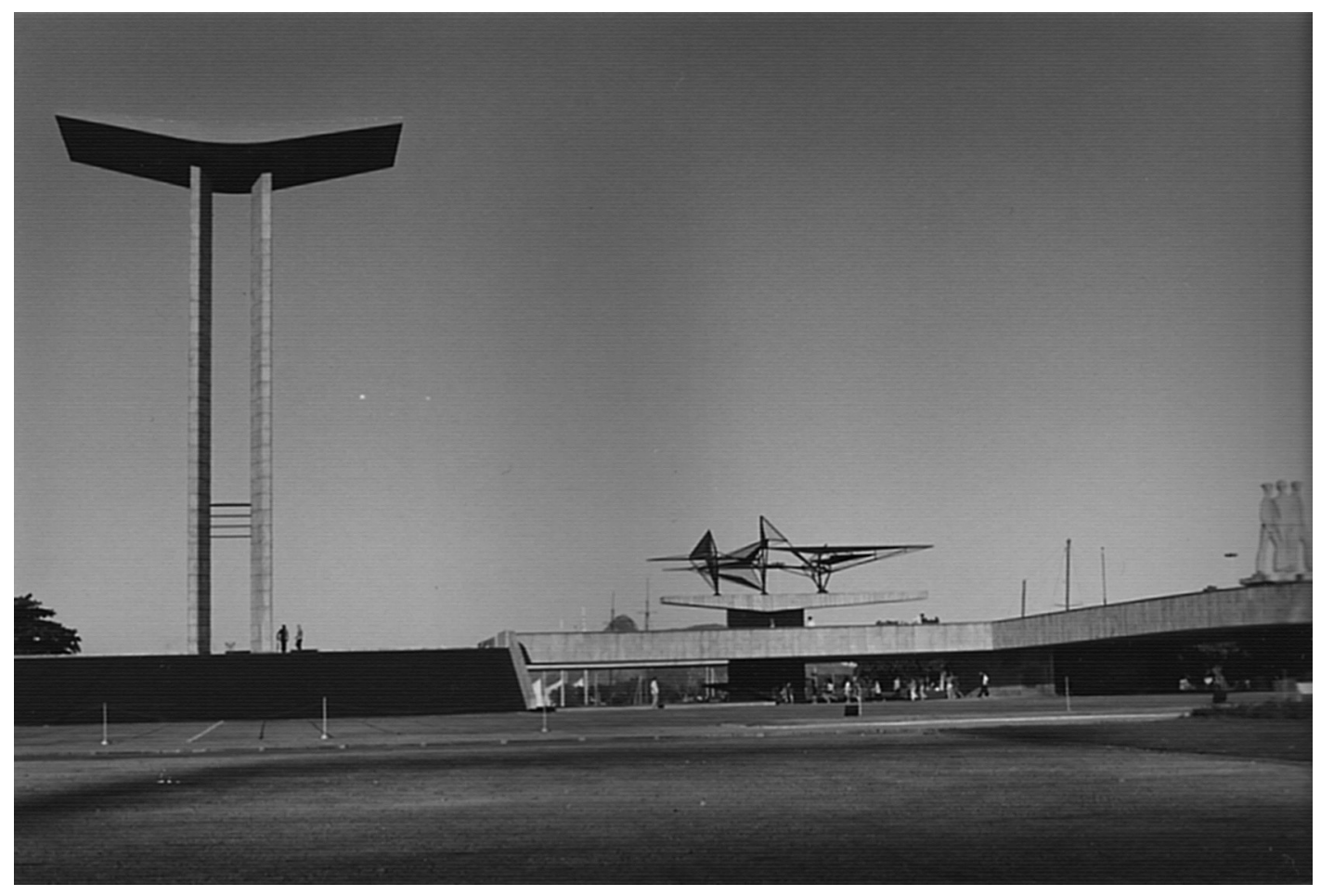

Figura 8 - Helio Ribas e Marcos Konder. Monumento aos Mortos na Segunda Guerra Mundial. Fotografia do autor.

21 Entrevista de Marcos Konder ao autor em 5 abr. 2004.

22. Suas dimensões foram definidas através de fotografias de várias simulações na maquete (Idem). ficam a administração e o mausoléu - este último, ventilado e iluminado pelo espelho d'água em cascatas.

A inspiração para o túmulo do soldado desconhecido veio daquele existente no Arco do Triunfo, em Paris: um pórtico abrigando o fogo simbólico ${ }^{21}$. A opção por dois pilones lembra o Monumento aos Mortos na Defesa do Canal de Suez, de Michel Roux-Spitz ou o Canadian Memorial (1936), do escultor Walter Allward, embora nenhum dos dois projetos seja mencionado pelos arquitetos. A laje curva que arremata os pilones foi tirada de Le Corbusier, em Chandigarh $^{22}$.

Se, para Lucio Costa, a plataforma elevada recupera o antigo mirante existente no Passeio Público de Mestre Valentim (MARINHO; NETTO, [s. d.]), em uma dupla referência à cultura arquitetônica e à integração do monumento ao local, sua organização em relação com a paisagem é muito semelhante ao templo a Minerva erguido por Grandjean de Montigny, para as festividades da aclamação de D. João VI, em 1818 . Tanto em um como no outro aparece a mesma contraposição entre racionalidade geométrica da arquitetura e paisagem ao fundo; se Montigny abraça a (atual) Praça XV com duas colunatas simétricas (em U), colocando o templo a Minerva ao centro, como marco vertical e organizador da percepção do conjunto, no Monumento aos Pracinhas, uma ala da plataforma elevada (em L) avança e delimita o espaço horizontal como uma 
praça, em oposição ao acento vertical modernamente assimétrico do túmulo do soldado desconhecido; ambos deixando desimpedida ao máximo a visão da baía desde o solo, criando uma escadaria de acesso a um plano elevado onde está o elemento hierarquizador da composição.

As diferenças ficam por conta da linguagem, da técnica construtiva e do caráter do programa la sobriedade do monumento fúnebre e o colorido festivo do pavilhão cerimonial) e em função do aspecto aristocrático de um em oposição ao aspecto democrático do outro.

Mas é propriamente a linguagem que parece ser a maior inovação do monumento moderno. A substituição do simbólico-figurativo, entretanto, não pôde ser completa. A síntese das artes, em uma obra de caráter simbólico, cuja arquitetura se baseia em formas geométrico-abstratas, não pode prescindir de uma linguagem mais clara. Portanto, nada de abstração geométrica na pintura e na escultura - lembre-se que, a essa altura, a batalha pela abstração no Brasil já havia sido deflagrada, desde pelo menos a exposição Do figurativismo ao abstracionismo, realizada em 1949 em São Paulo, no Museu de Arte Moderna ${ }^{23}$.

Daí os painéis de Anísio Medeiros. Da mesma forma, o painel bidimensional abstrato sugerido pelos projetistas transformou-se, nas mãos de Júlio Catelli, em leve escultura, não obstante, com "ares" de avião (Figura 8). E o movimentado conjunto escultórico imaginado inicialmente pelos arquitetos quase virou uma Pietà ${ }^{24}$. Se uma Pietà se aproximava muito mais do sentimento daqueles que perderam familiares e amigos, em se tratando de um monumento nacional, onde a pátria (e não os pais) homenageava seus filhos, ela se mostrava inadequada ao discurso enaltecedor do herói militar, cujo sacrifício pessoal conduziu à vitória coletiva. Donde a forma final adotada, absolutamente retórica (Figura 9).

Não menos significativa foi a contribuição do engenheiro calculista (e poeta) Joaquim Cardozo. Nos primeiros estudos, o suporte do grupo escultórico principal e da parte em balanço da plataforma elevada era um pesado bloco. Posteriormente, aparece um apoio assimétrico (em V) que, para o engenheiro, desequilibrava a composição ${ }^{25}$. $\bigcirc$ desenho final, dois troncos de pirâmide invertidos entre si e que se interpenetram - os apoios internos no mausoléu repetem, de maneira adaptada, a forma desse grande apoio externo - é bem mais dramático, como, provavelmente, percebeu Vilanova Artigas. $\bigcirc$ arquiteto paulista re-interpretou o tema, utilizado também por Rino Levi no projeto do Hospital Albert Einstein em São Paulo (c. 1958), no projeto para a Faculdade de Arquitetura e Urbanismo da Universidade de São Paulo (196 1-69) ${ }^{26}$.

Bruand (1999, p. 264) considerou a obra especialmente significativa: "ela se inscreve com vivacidade na tradição iniciada pelo Ministério da Educação, porém é bem contemporânea de Brasília por seu vocabulário, ao mesmo tempo simples e expressivo, e por sua preocupação com a integração a um conjunto urbano ordenado". Com efeito, não seria forçada uma aproximação entre o monumento e o Congresso Nacional em Brasília: ambas as obras têm como ponto focal dois elementos verticais que acabam por constituir um elemento único
23. Ao contrário da situação na época da construção do Ministério da Educação e Saúde, momento em que, praticamente, não se falava sobre arte abstrata no Brasil.

24. Entrevista ao autor em 5 abr. 2004.

25. Algum tempo antes, Cardozo havia publicado um artigo sobre as características da arquitetura brasileira naquele momento, destacando o tratamento diferenciado dispensado aos pilotis: "os próprios pilotis dos primeiros tempos da arquitetura moderna transformaram-se, assinalando agora com maior agudeza esse 'canto dos pontos de apoio' de que nos fala Perret" (1955, p.9).

26. Cardozo pode ter, assim, involuntariamente contribuído para a constituição da poética da arquitetura paulista. 


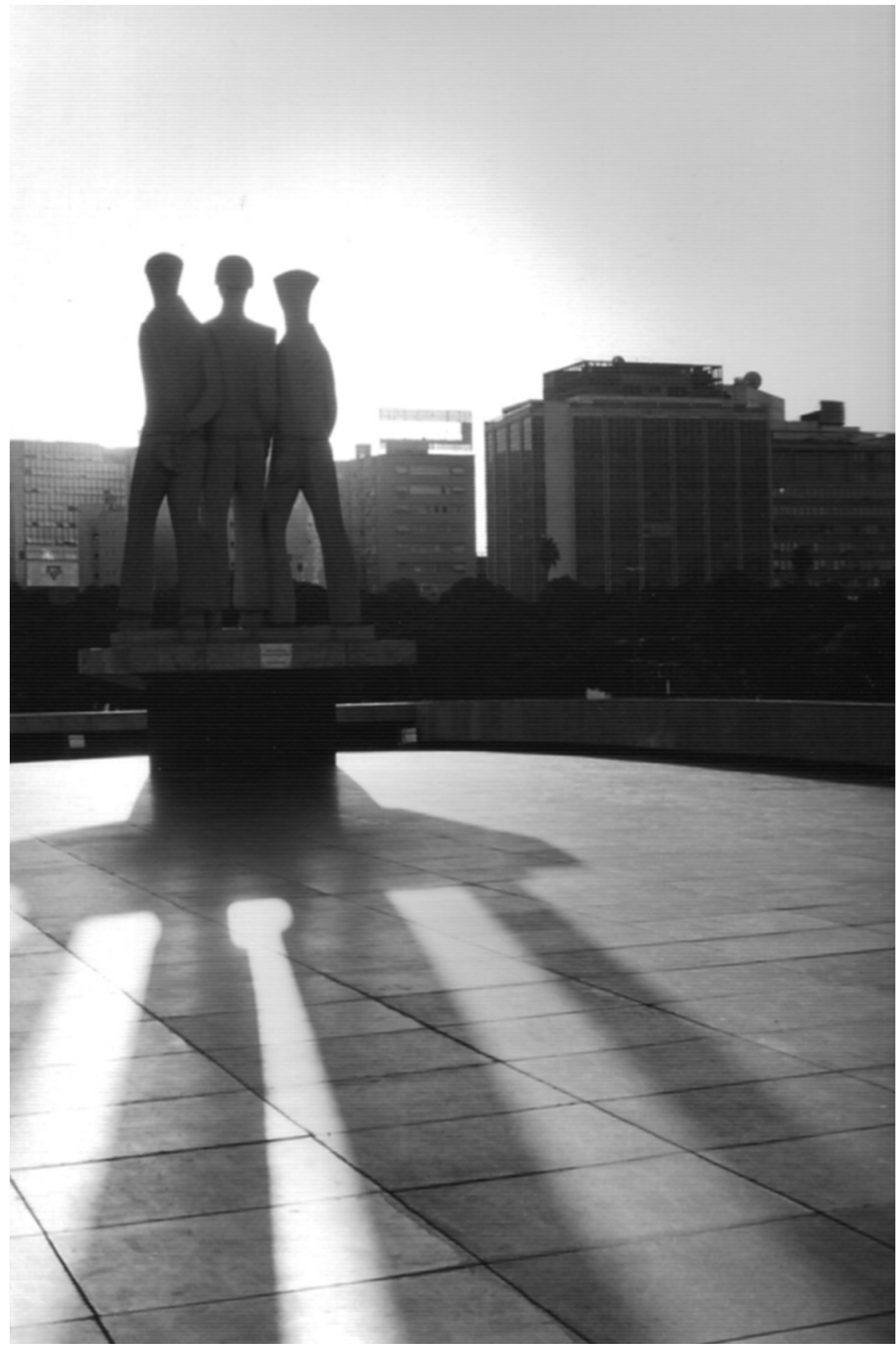

Figura 9 - Alfredo Ceschiatti. Grupo escultórico no Monumento aos Mortos na Segunda Guerra Mundial. Fotografia do autor. 
em termos perceptivos; colocado assimetricamente sobre uma plataforma; que abriga formas livres (esculturas ou cascas) menores.

$\bigcirc$ próprio Le Corbusier havia assinalado isso quando de sua última visita ao Brasil. Na carta de despedida - Uma palavra para meus amigos do Brasil -, redigida em dezembro de 1962, o arquiteto franco-suíço lembra Brasília, Lucio Costa e Niemeyer, o Ministério da Educação e Saúde (MES), as obras de Reidy e o monumento aos mortos da guerra ${ }^{27}$.

Esse ar de família, diga-se de passagem, refere-se à condição monumental de todas essas obras, a partir do caminho aberto pelo MES, monumento por excelência da arquitetura moderna brasileira (e mundial). Afinal, todo tema de projeto tornava-se passível de ser formalizado como monumento, não só os de forte apelo cultural, como o Museu de Arte Moderna, de Reidy (1953-68), mas qualquer outro, desde a habitação popular lo conjunto habitacional Pedregulho - 1947-52, do mesmo Reidy $\left.\right|^{28}$ até toda uma cidade (Brasília).

Em suma, o monumento aos pracinhas constitui um acerto quer em termos de funcionalização da representação da morte - no sentido da construção de um discurso cívico-patriótico ${ }^{29}$ - plasmado a partir de um diálogo entre formas arquitetônico-abstratas e plástico-figurativas inseridas no espaço público, quanto em termos da linguagem arquitetônica utilizada.

\section{enigma da esfinge: arquitetura moderna e monumentos}

Sem meias palavras, o caminho aberto pelo MES é exatamente o da nova monumentalidade. Desde esse prisma, o sucesso internacional da arquitetura moderna brasileira é menos a curiosidade despertada pelo milagre de uma arquitetura exemplar em um país periférico ou a inflexão com características culturais locais no vocabulário do modernismo arquitetônico internacional e mais a capacidade em (re)elaborar esse mesmo vocabulário, com maestria e eficácia invejáveis, no sentido da representação simbólica de valores ${ }^{30}$. E o Monumento aos Pracinhas não constitui peça menor nesse quebra-cabeça. Pelo contrário, mesmo que Marcos Konder e Hélio Ribas fossem recém-formados desconhecidos, a linguagem de seu projeto era bastante "familiar"

É sintomático, sob esse aspecto, o fato de que os finalistas do concurso para o Monumento ao Brasil na Guerra, promovido por uma associação de professores nos anos 1940, tenham sido, todos, escultores; ao passo que, no concurso para o Monumento aos Pracinhas, realizado pelo Estado na década de 1950, os finalistas eram - todos - arquitetos ou equipes chefiadas por arquitetos. A hegemonia alcançada pela arquitetura carioca no panorama da arquitetura brasileira em meados da década de 1940 estende-se, nos anos 1950, aos projetos de monumentos. Dupla hegemonia, nesse sentido, no panorama da arquitetura e, para além deste, no campo de atuação profissional que, ampliado, passa a abraçar áreas disputadas com outros profissionais. E,
27.Tal carta aparece publicada em vários livros, como em Xavier (1987).

28. Sobre Reidy, conferir Conduru (2006).

29. Consultar Mauad e Nunes (1999).

30. Cavalcanti já havia observado que "um ponto que muito contou na conquista do aval de um Estado sequioso de marcar sua presença em grande escala foi a habilidade dos 'modernos' em lidar com o monumental" (1995, p. 147).

31. Konder relata que "a última vez que Le Corbusier visitou o Rio, a filha do Lucio [Maria Elisa] o levou para ver obras importantes; levou no Museu de Arte Moderna do Reidy que é do lado, mas aí como eu não estava naquele 'grupinho', ela o colocou no carro para levá-lo ao Leblon, onde havia uma casa do Sérgio Bernardes; quando eles passaram em frente ao monumento, Le Corbusier disse 'eu quero ver essa obra', só então eles pararam e ele ficou uma hora por lá". Entrevista ao autor em 5 abr. 2004 
ao reconhecer sua própria produção como "monumentos" - em 1947 foi tombada pelo SPHAN a Capela de São Francisco, na Pampulha, e, no ano seguinte, o Ministério da Educação - sob a chancela do Estado, o grupo moderno dava o tiro de misericórdia e tomava o último baluarte dos acadêmicos e conservadores: a arquitetura monumental.

Paradoxalmente, o processo de formação da arquitetura moderna brasileira, que se manifesta exemplarmente com a construção do MES, ocorre na ditadura de Getúlio Vargas, ao passo que seu clímax e ocaso, a construção de Brasília, acontece no governo democrático de Juscelino Kubitschek.

De qualquer forma, a articulação entre monumento e cotidiano, tal como identificada em Brasília lautonomia do setor residencial apesar de sua articulação com o eixo monumental) e no Monumento aos Pracinhas (ao mesmo temo espaço de "lazer" integrado ao Parque do Flamengo e lugar cerimonial e cívico) constitui uma das chaves para a compreensão do monumento moderno. Como no MES, onde a vida cotidiana e apressada segue indiferente, mas abrigada por seus pilotis, ambas as esferas são tratadas conjuntamente, de maneira ao mesmo tempo independente e interdependente. Assim, os valores acrisolados em um monumento, ao invés de impostos, podem ser descobertos e reconhecidos de maneira livre e autônoma pelo sujeito.

\section{REFERÊNCIAS}

AGULHON, Maurice. Marianne au combat: L'imagerie et la symbolique républicaines de 1789 à 1880. Paris: Flamarion, 1979.

BRUAND, Yves. Arquitetura Contemporânea no Brasil. São Paulo: Perspectiva, 1999.

CAVALCANTI, Lauro. As preocupações do belo. Rio de Janeiro:Taurus, 1995.

CARDOZO, Joaquim.Arquitetura Brasileira, características mais recentes. Módulo, Rio de Janeiro, n. 1, p. 6-9, 1955.

COMAS, Carlos. Protótipo e monumento, um ministério, o ministério. Projeto, São Paulo, n. 102, p. 137-149, 1987.

CONDURU, Roberto. Razão contra poder: Affonso Eduardo Reidy e a monumentalidade arquitetônica moderna. In: PESSÔA, J. et al. (Orgs.). Moderno e Nacional. Niterói: EdUFF, 2006. p. 67-82.

COSTA, Lúcio. Código de Obras de Brasília. In: Sobre Arquitetura. Porto Alegre: Centro dos Estudantes Universitários de Arquitetura, 1962. p. 324-326.

COSTA, Octavio. Trinta anos depois da volta: o Brasil na II Guerra Mundial. Rio de Janeiro: Biblioteca do Exército, 1976.

FERRAZ, Francisco.A guerra em tempo de paz. Nossa bistória, Rio de Janeiro, n. 15, p. 31-35, 2005. 
FRAMPTON, Kenneth. Modern architecture: a critical history. London:Thames \& Hudson, 1985.

GOODWIN, Philip. Brazil builds. New York: MoMA, 1943.

HANDLIN, David. American Architecture. London:Thames and Hudson, 2004.

HEATHCOTE, Edwin. Monument builders: modern architecture and death. Londres:Academy, 1999.

HERF, Jeffrey. O modernismo reacionário: tecnologia, cultura e política na República de Weimar e no III Reich.Trad. Cláudio Ramos. São Paulo: Ensaio, 1993.

JOLY, Jacques. La France des années 60. Le pouvoir sans lieux ou la monumentalité inversée. In: SABATIER, G.; GOMES R. Lugares de poder. Europa séculos XV a XX. Lisboa: Fundação Calouste Gulbenkian, 1998. p. 364-391.

LIERNUR, Jorge. "The South American Way": el "milagro" brasileño, los Estados Unidos y la Segunda Guerra Mundial (1939-43). Block, Buenos Aires, n. 4, p. 23-41, 1999.

LISSOVSKY, M.; SÁ, P. (Orgs.). Colunas da Educação: a construção do Ministério da Educação e Saúde (1935-1945). Rio de Janeiro: IPHAN, 1996.

MARINHO, Hélio; NETTO, Marcos Konder. Monumento Nacional aos Mortos da Segunda Guerra Mundial: memorial dos arquitetos. Módulo, Rio de Janeiro, n. 6, p. 60-65, 1955.

Monumento Nacional aos Mortos da Segunda Guerra Mundial. Rio de Janeiro: (mimeog.), s/d.

MAUAD,Ana; NUNES, Daniela. Discurso sobre a morte consumada: Monumento aos Pracinhas. In: KNAUSS, Paulo (Org.). Cidade vaidosa: imagens urbanas do Rio de Janeiro. Rio de Janeiro: Sette Letras, 1999. p. 73-92.

PROST, Antoine. Les monuments aux morts. In: NORA, Pierre. Les lieux de mémoire, 1. Paris: Gallimard, 1997.

RIGOTTI,Ana. Brazil Declives. Block, Buenos Aires, n. 4, p. 78-86, 1999.

SHERMAN, Daniel. The construction of memory in interwar France. Chicago:The University of Chicago Press, 1999.

SILVA, Geraldo G. da. O atentado terrorista e a estética do oprimido. Projeto, São Paulo, n. 122, p. 196-197, 1989 .

VOVELLE, Michel. Ideologias e mentalidades. São Paulo: Brasiliense, 1987.

XAVIER,Alberto (Org.). Arquitetura moderna brasileira: depoimento de uma geração. São Paulo: Associação Brasileira de Ensino de Arquitetura, 1987.

Artigo apresentado em 6/2007. Aprovado em 9/2007. 